\title{
Kinetic Constants for Receptor-dependent and Receptor-independent Low Density Lipoprotein Transport in the Tissues of the Rat and Hamster
}

\author{
David K. Spady, Jonathan B. Meddings, and John M. Dietschy \\ Department of Internal Medicine, The University of Texas Health Science Center at Dallas, \\ Southwestern Medical School, Dallas, Texas 75235
}

\begin{abstract}
In this study, carried out in the rat and hamster, the receptordependent low density lipoprotein (LDL) transport process in each organ was characterized in terms of its maximal uptake rate $\left(\mathrm{J}^{\mathrm{m}}\right)$ and Michaelis constant $\left(\boldsymbol{K}_{\mathrm{m}}\right)$, while the rate of receptorindependent uptake was defined in terms of its proportionality constant (P). The highest $J^{\mathrm{m}}$ values of $50-126 \mu \mathrm{g} / \mathrm{h}$ per $\mathrm{g}$ were found in the liver and endocrine glands in both species and receptor-dependent uptake also was detected in other organs like spleen, kidney, and intestine. The $K_{\mathrm{m}}$ values were essentially the same in all of the organs and equaled $\sim 90 \mathrm{mg} / \mathrm{dl}$ in both species. The receptor-independent uptake constants also were similar in the two species and were highest in the spleen, liver, and intestine. From these values for $\mathrm{J}^{\mathrm{m}}, K_{\mathrm{m}}$, and $\mathrm{P}$, it was possible to construct theoretical curves that predict the plasma LDL-cholesterol concentration and fractional catabolic rate given any alteration in LDL-cholesterol production or the magnitude of receptor-dependent LDL transport in any organ of the rat or hamster.
\end{abstract}

\section{Introduction}

Low density lipoprotein (LDL) circulating in the plasma is derived principally from the metabolism of very low density lipoprotein and, possibly, from direct secretion by the liver (1). This lipoprotein is removed from the plasma by uptake into a variety of tissues by either receptor-dependent $(2,3)$ or receptorindependent (4) transport processes. In several experimental animals and in man, receptor-dependent clearance usually accounts for $60-80 \%$ of LDL degradation, while receptor-independent uptake accounts for the remaining $20-40 \%$ of LDL clearance (5-10). However, these values apply only to animals and man with normal circulating concentrations of LDL-cholesterol. These figures would vary at other plasma cholesterol levels since the receptor-dependent transport of LDL in vivo has been found to be a saturable process $(9,11)$, while the rate of LDL degradation by the receptor-independent process is a linear function of the plasma LDL-cholesterol concentration $(4,12)$. Thus, for example, the percentage of LDL clearance by the receptor-dependent process would increase at lower plasma LDL-cholesterol concentrations and decrease at higher concentrations even though the absolute amount of LDL receptor activity was kept

\footnotetext{
Address correspondence to Dr. Dietschy.

Received for publication 23 September 1985 and in revised form 7 January 1986.
}

J. Clin. Invest.

(C) The American Society for Clinical Investigation, Inc. 0021-9738/86/05/1474/08 $\$ 1.00$

Volume 77, May 1986, 1474-1481 constant (as might occur, for example, with changes in LDL production rates).

The receptor-dependent and independent LDL transport activities manifest in vivo are not distributed uniformly in all organs $(4,9)$ and, in addition, are subject to different modes of regulation $(9,10,13)$. Furthermore, it is possible that the kinetic constants of LDL transport that define the relationship between the plasma LDL-cholesterol concentration and the rate of uptake also vary markedly among the different organs. Thus, in any physiological situation, the steady state plasma LDL-cholesterol concentration is determined by the rate of LDL production relative to the rate of LDL uptake by both the receptor-dependent and independent transport processes located in all of the organs of the body. From these considerations, it is obvious that the mechanisms of regulation of plasma LDL-cholesterol levels can only be understood if detailed kinetic data are available on the mechanisms of LDL uptake in all organs in a given experimental animal or in man.

For this reason, we undertook these studies to define the kinetic characteristics of both the receptor-dependent and receptor-independent transport processes in all major organs of both the rat and hamster under conditions where total LDL receptor activity was kept constant. These data provided the basis for defining the maximal transport rates and Michaelis constants for receptor-dependent transport and the proportionality constants for receptor-independent uptake in the organs of these two species. With such data defined, it was also possible to construct whole-animal LDL transport curves that predict the plasma LDL-cholesterol concentration under any circumstance in which there had been a systematic alteration in the rate of LDL production and/or receptor-dependent or independent transport in any organ in the body.

\section{Methods}

Animal preparation. Female Sprague-Dawley rats (Charles River Breeding Laboratories, Inc., Wilmington, MA) and male Golden Syrian hamsters (Charles River Breeding Laboratories, Inc.) were purchased in the weight ranges of $125-150$ and $80-100 \mathrm{~g}$, respectively. Both groups of animals were then housed a minimum of $2 \mathrm{wk}$ in isolation rooms with alternating 12-h periods of light and darkness, and allowed free access to water and a low-cholesterol rodent diet (Wayne Laboratory Animal Diets, Allied Mills, Inc., Chicago, IL). On the morning of the experiments, at the middark point of the light cycle, each animal was fitted with an indwelling femoral vein catheter $(9,14)$.

Lipoprotein preparations. Plasma was obtained from donor animals maintained on a low-cholesterol diet or from human subjects fasted overnight. The LDL fraction was isolated in the density range of 1.020$1.055 \mathrm{~g} / \mathrm{ml}$, purified, and labeled with $\left[1-{ }^{14} \mathrm{C}\right]$ sucrose as previously described in detail $(4,5,9)$. The human $\mathrm{LDL}$ also was subjected to reductive methylation $(4,15)$. Total LDL transport in the organs of the rat and hamster was measured using the respective homologous preparation (LDL obtained from rat plasma and LDL obtained from hamster plasma 
[hamLDL] ${ }^{1}$ ), while the methylated human LDL (methyl-hLDL) was used to quantitate receptor-independent LDL uptake in the tissues of both species (4). In all cases, the lipoprotein preparations were passed through 0.45- $\mu \mathrm{m}$ filters (Millipore Corp., Bedford, MA) and administered to the experimental animals within 12-24 $\mathrm{h}$ after preparation.

Determination of rates of total and receptor-independent $L D L$ transport. Rates of LDL uptake in vivo by the different organs of the rat and hamster were determined using the primed-continuous infusion technique described in detail elsewhere $(4,9,11)$. At the beginning of each study the animals were given a rapid injection of a solution containing varying amounts of both unlabeled and $\left[{ }^{14} \mathrm{C}\right]$ sucrose-labeled LDL. This injection was immediately followed by a continuous infusion of the same LDL preparation at a rate equal to the hourly plasma clearance rate. In this manner, the concentration of LDL-cholesterol in the circulating plasma could be abruptly elevated to any desired value and then maintained at that value over the ensuing 4-h experimental period (11). The animals were then killed and aliquots of plasma and all major organs were obtained and assayed for ${ }^{14} \mathrm{C}$ content $(4,16)$. Since the specific activity of the plasma LDL was constant over the 4-h infusion period and since tissue accumulation of LDL was linear with respect to the time of infusion (11), the rate of LDL transport (J) into each organ could be expressed as micrograms of LDL-cholesterol taken up each hour by $1 \mathrm{~g}$ wet weight of that tissue $(\mu \mathrm{g} / \mathrm{h}$ per $\mathrm{g})$. These data also were expressed as clearance values that gave the microliters of plasma cleared entirely of its LDL content per $\mathrm{h}$ per $\mathrm{g}(\mu \mathrm{l} / \mathrm{h}$ per $\mathrm{g})$. It should be emphasized that the intravenous infusion of even large amounts of LDL-cholesterol over this 4-h period did not alter LDL receptor activity in any organ in the rat or hamster (11).

Determination of rates of cholesterol synthesis. Rates of cholesterol synthesis were determined in vivo using $\left[{ }^{3} \mathrm{H}\right]$ water as previously described in detail $(17,18)$.

Calculations. The theoretical considerations associated with the calculation of transport constants in these studies are shown diagrammatically in Fig. 1. LDL is present in the bulk phase of the capillary plasma at a concentration equal to $C_{1}$. The concentration of lipoprotein at the surface of the parenchymal cells of any organ, however, may be lower and is designated as $C_{2}$. The extent to which $C_{2}$ is less than $C_{1}$ depends upon the resistance to diffusion ( $R$ ) encountered by the LDL molecule in crossing the diffusion barrier between the bulk phase of the capillary plasma and the parenchymal cell surface. This resistance factor is, in turn, dependent upon three parameters including the area of the barrier available to the LDL molecule for diffusion $\left(S_{w}, \mathrm{~cm}^{2} / \mathrm{g}\right)$, the effective diffusion distance $(\mathrm{d}, \mathrm{cm})$, and the free diffusion coefficient of the lipo- protein molecule $\left(\mathrm{D}, \mathrm{cm}^{2} / \mathrm{h}\right)(19)$. In these studies, all three of these values have been combined into a single resistance term so that $R$ has the units of $\mathrm{g} \mathrm{h} / \mathrm{cm}^{3}$. Using this value, the concentration of LDL at $\mathrm{C}_{2}$ can be calculated from the following relationship (20), where $J_{t}$ equals the total flux of LDL between $C_{1}$ and $C_{2}$ :

$C_{2}=C_{1}-J_{t} R$.

LDL molecules arriving at the parenchymal cell surface are transported into the cell by either receptor-dependent or independent mechanisms. In these, and in other studies (4), the observed velocity of receptorindependent uptake $\left(J_{i}\right)$ has been shown to be linear with respect to the LDL concentration so that the rate of tissue uptake by this process is described by the following equation (20):

$J_{i}=\left(C_{2}\right)(P)$.

Eq. 2

The $P$ term is analogous to a passive permeability coefficient and defines the micrograms of LDL-cholesterol taken up each $h$ by $1 \mathrm{~g}$ of a particular organ for each $\mathrm{mg} / \mathrm{dl}$ of LDL-cholesterol present at $\mathrm{C}_{2}(\mu \mathrm{g} / \mathrm{h}$ per $\mathrm{g}$ per $\mathrm{mg} / \mathrm{dl}$ ). Thus, the receptor-independent uptake constant (P) equals $\mathrm{J}_{\mathrm{i}} /$ $C_{2}$ while the apparent constant $\left(P^{*}\right)$ equals $J_{i} / C_{1}$. In these studies, $P^{*}$ values were determined for each organ by fitting linear regression curves to data describing the rates of receptor-independent methyl-hLDL uptake in each tissue at different plasma methyl-hLDL concentrations as illustrated, for example, in Fig. 3. In contrast, LDL uptake by the receptordependent process $\left(J_{d}\right)$ in vivo has been shown to be saturable $(9,11)$ and so is described by the following equation (20), where $\mathrm{J}^{\mathrm{m}}$ and $K_{\mathrm{m}}$, respectively, equal the maximal transport velocity and Michaelis constant for the receptor-dependent process:

$\mathrm{J}_{\mathrm{d}}=\frac{\mathrm{C}_{2} \mathrm{~J}^{\mathrm{m}}}{K_{\mathrm{m}}+\mathrm{C}_{2}}$.

However, in the experimental situation, the rates of LDL uptake are always measured at particular LDL-cholesterol concentrations in the plasma $\left(C_{1}\right)$ while the concentration at the parenchymal cell interface $\left(C_{2}\right)$ cannot be experimentally determined. Furthermore, such LDL uptake rates always include a receptor-independent component. However, equations 2 and 3 can be combined to give an expression that defines the rate of total LDL uptake $\left(\mathrm{J}_{t}\right)$ as the sum of the receptor-dependent $\left(J_{d}\right)$ and receptor-independent $\left(J_{i}\right)$ processes. In addition, these two expressions can be rewritten in terms of the plasma LDL-cholesterol concentration $\left(C_{1}\right)$ since $C_{2}$ is equal to the term $C_{1}-J_{t} R$ (eq. 1). Thus, the rate of total LDL uptake by any tissue at any concentration of LDLcholesterol in the plasma is given by the following expression (20-22):

$$
J_{t}=\frac{\begin{array}{l}
\left(K_{m}+C_{1}+P_{m}+2 K_{m}+C_{1}+J^{m} R\right) \\
-\sqrt{\left(K_{m}+C_{1}+P R K_{m}+2 P R C_{1}+J^{m} R\right)^{2}-4\left[P R\left(P R C_{1} K_{m}+P R C_{1}{ }^{2}+R^{m} C_{1}+C_{1} K_{m}+C_{1}{ }^{2}\right)+J^{m} C_{1} R\right]}
\end{array}}{2 R(P R+1)} .
$$

Thus, the shape of the curve defining the kinetic relationship between $J_{t}$ and $C_{1}$ is determined by the values of the four variables $P, R, J^{m}$, and $K_{m}$. Curves were fitted to experimental data relating $J_{t}$ to $C_{1}$ as, for example, those shown in Fig. 4, using true nonlinear regression analysis

1. Abbreviations used in this paper: $\mathrm{C}_{1}$, concentration of LDL-cholesterol in capillary plasma; $\mathrm{C}_{2}$, concentration of LDL-cholesterol at the membrane surface of parenchymal cells; FCR, fractional catabolic rate; hamLDL, LDL obtained from hamster plasma; J, rate of LDL transport; $\mathrm{J}^{\mathrm{m}}$, maximal uptake rate of $L D L$ via the receptor-dependent pathway; $K_{\mathrm{m}}$, true Michaelis constant for the receptor-dependent LDL transport system defined in terms of $\mathrm{C}_{2} ; K_{\mathrm{m}}^{*}$, apparent Michaelis constant defined in terms of $C_{1}$; methyl-hLDL, methylated human LDL; $P$, true proportionality constant for LDL transport via the receptor-independent pathway defined in terms of $\mathrm{C}_{2} ; \mathrm{P}^{*}$, apparent proportionality constant for the receptor-independent pathway defined in terms of $C_{1} ; R$, resistance incurred by LDL in diffusing from capillary plasma to the parenchymal cell surface of any organ. based on a previously published method (23). Using initial parameter values estimated by visual inspection of the experimental data, sequential changes in these parameters were made by the program until the sum of the residuals squared was minimized. This procedure was continued until the change in all parameters was $<1 \%$ of the parameter values. This usually required $20-30$ iterations.

In the initial analysis of these data, the curve fitting process was allowed to provide values for all four parameters in equation 4 (see Results section). However, this initial analysis consistently yielded values for $\mathbf{R}$ that were so low $\left(<0.003 \mathrm{~g} \mathrm{~h} / \mathrm{cm}^{3}\right)$ that $C_{2}$ essentially equaled $C_{1}$ in all organs with demonstrable receptor-dependent LDL uptake. In this special circumstance a second expression can be derived that defines the relationship between $J_{t}$ and $C_{1}$ as follows:

$\mathrm{J}_{\mathrm{t}}=\frac{\mathrm{C}_{1} \mathrm{~J}_{\mathrm{m}}+\mathrm{PC}_{1} K_{\mathrm{m}}+\mathrm{PC}_{1}{ }^{2}}{K_{\mathrm{m}}+\mathrm{C}_{1}}$

Since $P$ equaled $P^{*}$ and $R$ was set equal to 0 , equation 5 could be fitted 


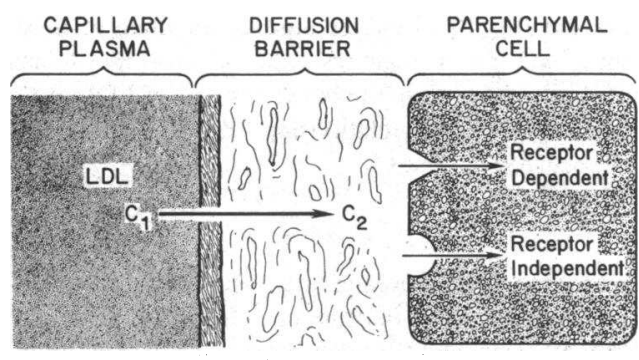

Figure 1. Model used in formulating the transport constants for LDL uptake by various tissues. In order to be taken up by the parenchymal cells of any organ, LDL must move from the capillary plasma (at a concentration of $C_{1}$ ) to the pericellular fluid adjacent to the cell membrane (at a concentration of $\mathrm{C}_{2}$ ). The resistance encountered by the LDL molecule in moving from $C_{1}$ to $C_{2}$ is designated $R$ and is dictated by the effective area available for diffusion $\left(\mathrm{S}_{\mathrm{w}}\right)$, the effective diffusion distance (d), and the free diffusion coefficient for the LDL molecule (D) $(20,21)$.

to the observed data and the best-fit values for $K_{\mathrm{m}}$ and $\mathrm{J}^{\mathrm{m}}$ obtained. Under these conditions an average of 10-15 iterations were required to obtain the best-fit curve. The goodness of fit of the data to either equation was defined in terms of an $\mathrm{r}^{2}$ value, adjusted for the number of parameters fitted, while the variance of the values for each parameter was defined as $\pm 1 \mathrm{SD}$.

\section{Results}

These detailed studies of the transport kinetics of receptor-dependent and independent LDL uptake in vivo were carried out in two species, the rat and hamster. As previously reported (24, 25 ), the rat has an exceptionally high rate of whole-body cholesterol synthesis which, in the animals used in these studies, equaled $120 \pm 10 \mathrm{mg} / \mathrm{d}$ per $\mathrm{kg}$ body weight. In contrast, wholebody cholesterol synthesis in the hamsters was much closer to those values observed in young human subjects and equaled $19 \pm 2 \mathrm{mg} / \mathrm{d}$ per $\mathrm{kg}$ body weight. This difference was even more striking when rates of hepatic sterol synthesis in vivo were compared. The livers of the female rats synthesized $\sim 70 \mu \mathrm{g}$ of cholesterol per $h$ per $g$ while those of the male hamsters synthesized only $\sim 1 \mu \mathrm{g} / \mathrm{h}$ per $\mathrm{g}$. Because of these high rates of basal cholesterol synthesis, the rat responds to most changes in sterol balance with an appropriate change in synthesis and there is no alteration in LDL transport by the liver or other organs $(4,5,10)$. In contrast, the hamster, like man, has a much more limited capacity to adapt to changes in cholesterol balance by changing synthesis rates and so often responds to changes in cholesterol balance by altering LDL clearance rates $(9-11,26)$. Thus, a detailed kinetic analysis was carried in these two species which, in a sense, represent the extremes of behavior with respect to cholesterol and LDL metabolism.

Homologous and methyl-hLDL uptake in the rat and hamster. In previous studies carried out both in vitro (27) and in vivo (28), it has been reported that heterologous and reductively methylated LDL preparations interact poorly with the LDL receptor system. Furthermore, it has been recently shown that heterologous LDL that has been reductively methylated totally loses its ability to bind to the LDL receptor in vivo and is degraded in the intact animal at a minimal rate (4). For this reason, methyl-hLDL was utilized in these studies to characterize and quantitate receptor-independent LDL uptake in both the rat and hamster while the appropriate homologous LDL preparation was used to measure total LDL uptake by both the receptordependent and independent processes.

Fig. 2 shows an example of the kinetic curves generated by this method when the plasma LDL-cholesterol concentration in the hamster was varied over a very wide range using either hamLDL or methyl-hLDL, and LDL uptake was then quantitated in the adrenal gland. As is apparent, the uptake (Fig. $2 A$ ) of methyl-hLDL by the receptor independent pathway increased linearly with respect to the plasma LDL-cholesterol concentration. Thus, when expressed as a plasma clearance value, receptorindependent LDL clearance by the adrenal gland was constant at $3.5 \pm 0.1 \mu \mathrm{l} / \mathrm{h}$ per $\mathrm{g}$ (Fig. $2 \mathrm{~B}$ ). In contrast, the adrenal gland uptake of hamLDL manifested a complex relationship to plasma LDL cholesterol concentrations (Fig. $2 A$ ). Nevertheless, the appropriate regression curve could be fitted to these data which took into consideration the kinetics of both the receptor-dependent and independent transport processes (equation 4). When these same data were expressed in clearance terms (Fig. $2 \mathrm{~B}$ ), it is apparent that there was a marked decrease in adrenal gland clearance of LDL, from nearly $80 \mu \mathrm{l} / \mathrm{h}$ per $\mathrm{g}$ to $15 \mu \mathrm{l} / \mathrm{h}$ per $\mathrm{g}$, as the plasma hamLDL-cholesterol concentration was increased to nearly $500 \mathrm{mg} / \mathrm{dl}$. Curves such as these were generated for every major organ in the rat and hamster and were used to determine the kinetic constants for the receptor-dependent and independent transport processes in these organs.

Receptor-independent LDL uptake. When the plasma concentration of methyl-hLDL-cholesterol was varied from 0 to nearly $500 \mathrm{mg} / \mathrm{dl}$, the uptake of LDL by the receptor-indepen-

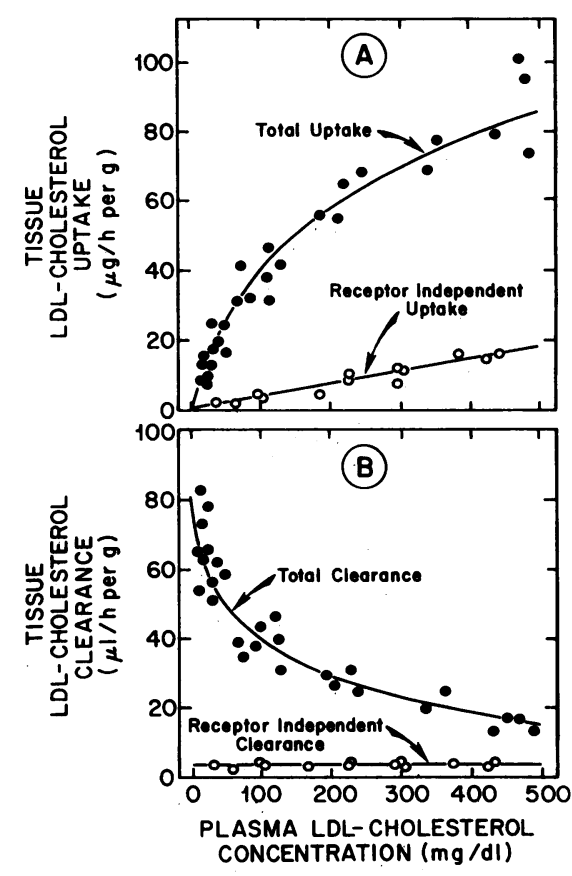

Figure 2. LDL-cholesterol uptake and clearance by the adrenal gland of the hamster. $A$ shows the rates of both hamLDL-cholesterol (total) and methyl-hLDL-cholesterol (receptor-independent) uptake in the adrenal gland at plasma LDL-cholesterol concentrations $\left(C_{1}\right)$ varying from 15 to $500 \mathrm{mg} / \mathrm{dl}$. $B$ shows the same data expressed as plasma clearance values. The curves were fitted, as described in Methods, to data points obtained in 28 (hamLDL) and 13 (methyl-hLDL) animals, respectively. 


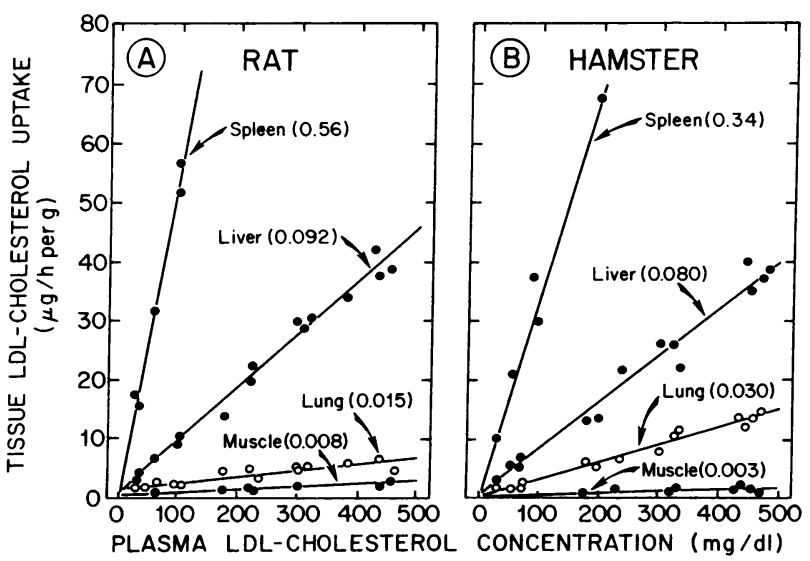

Figure 3. Receptor-independent LDL uptake in different organs of the rat and hamster. Rates of methyl-hLDL-cholesterol uptake at different concentrations of plasma methyl-hLDL-cholesterol are shown for various organs of the rat $(A)$ and hamster $(B)$. The numbers in parenthesis are the slopes of the fitted curves and represent the apparent receptor independent LDL uptake constants $\left(\mathrm{P}^{*}\right)$ for each organ. The curves were fitted to the data points obtained in 13-16 animals, although not all data points could be plotted in this figure.

dent transport process increased linearly with respect to the concentration of the lipoprotein in the plasma $\left(C_{1}\right)$ in every organ of the rat and hamster, as illustrated by the representative curves shown in Fig. 3. The slope of the linear regression curves fitted to these data yielded the apparent receptor-independent uptake constants $\left(\mathrm{P}^{*}\right)$ for each organ and these are listed in Table I for both species. This constant is analogous to a passive permeability coefficient and, for each organ, gives the absolute rate of LDLcholesterol uptake $(\mu \mathrm{g} / \mathrm{h}$ per $\mathrm{g})$ by the receptor-independent pathway for each $\mathrm{mg} / \mathrm{dl}$ concentration of LDL-cholesterol in the plasma.

As is apparent in both Fig. 3 and Table $I$, the values of $\mathrm{P}^{*}$ varied over 10-fold in the various organs but were similar in the two species in any given tissue. In both the rat and hamster, the highest $P^{*}$ values were found in the spleen $(0.34-0.56 \mu \mathrm{g} / \mathrm{h}$ per $\mathrm{g}$ per $\mathrm{mg} / \mathrm{dl})$. Relatively high constants also were found in liver (0.080-0.092) and small intestine (0.080-0.085) but were significantly lower in most other organs. In particular, organs like adipose tissue, skin, skeletal muscle, and brain had receptorindependent uptake constants that were all $<0.015 \mu \mathrm{g} / \mathrm{h}$ per $\mathrm{g}$ per $\mathrm{mg} / \mathrm{dl}$. Thus, every tissue appeared to be able to clear at least some LDL from the plasma by this receptor-independent pathway where the rate of uptake increased linearly with the plasma LDL-cholesterol concentration.

Receptor-dependent LDL uptake. Next, to determine the kinetic parameters for the receptor-dependent transport system, we measured rates of uptake of homologous LDL in all of the major organs of the rat and hamster at varying concentrations of the LDL preparation in the plasma. The relationship between the plasma LDL-cholesterol concentration $\left(C_{1}\right)$ and the uptake

Table I. Kinetic Constants for LDL Transport Into the Tissues of the Female Rat and Male Hamster

\begin{tabular}{|c|c|c|c|c|c|c|}
\hline \multirow[b]{3}{*}{ Tissue } & \multicolumn{3}{|l|}{ Rat } & \multicolumn{3}{|l|}{ Hamster } \\
\hline & \multirow{2}{*}{$\frac{\text { Receptor-independent* }}{\mathrm{P}^{*}}$} & \multicolumn{2}{|c|}{ Receptor-dependent\$ } & \multirow{2}{*}{$\frac{\text { Receptor-independent* }}{\mathrm{P}^{*}}$} & \multicolumn{2}{|c|}{ Receptor-dependentt } \\
\hline & & $K_{m}$ & $\mathbf{J}^{\mathbf{m}}$ & & $K_{\mathbf{m}}$ & $\mathbf{J}^{\mathbf{m}}$ \\
\hline & $\mu g / h$ per $g$ per $m g / d l$ & $m g / d l$ & $\mu g / h$ per $g$ & $\mu g / h$ per $g$ per $m g / d l$ & $m g / d l$ & $\mu g / h$ per $g$ \\
\hline Liver & $0.092 \pm 0.031$ & $114.2 \pm 2.5$ & $89.8 \pm 1.4$ & $0.080 \pm 0.025$ & $108.7 \pm 5.7$ & $126.0 \pm 9.6$ \\
\hline Adrenal gland & $0.028 \pm 0.007$ & $113.2 \pm 1.2$ & $102.8 \pm 4.9$ & $0.035 \pm 0.004$ & $81.6 \pm 4.0$ & $55.2 \pm 2.8$ \\
\hline Ovary & $0.061 \pm 0.025$ & $67.9 \pm 4.0$ & $49.5 \pm 3.0$ & $0.040 \pm 0.015$ & - & - \\
\hline Spleen & $0.560 \pm 0.105$ & $87.9 \pm 0.8$ & $354 . \pm 0.9$ & $0.340 \pm 0.060$ & $102.2 \pm 3.5$ & $15.1 \pm 1.0$ \\
\hline Kidney & $0.048 \pm 0.005$ & $96.3 \pm 0.7$ & $36.6 \pm 0.6$ & $0.015 \pm 0.002$ & $86.7 \pm 1.0$ & $5.5 \pm 1.7$ \\
\hline Small bowel & $0.085 \pm 0.029$ & $101.7 \pm 0.7$ & $7.4 \pm 0.2$ & $0.080 \pm 0.029$ & $75.9 \pm 1.6$ & $16.6 \pm 0.8$ \\
\hline Lung & $0.015 \pm 0.009$ & $\mathrm{ND} \S$ & ND & $0.030 \pm 0.005$ & ND & ND \\
\hline Colon & $0.028 \pm 0.010$ & ND & ND & $0.018 \pm 0.006$ & ND & ND \\
\hline Heart & $0.043 \pm 0.020$ & ND & ND & $0.042 \pm 0.027$ & ND & ND \\
\hline Stomach & $0.022 \pm 0.010$ & ND & ND & $0.023 \pm 0.014$ & ND & ND \\
\hline Adipose tissue & $0.012 \pm 0.008$ & ND & ND & $0.011 \pm 0.005$ & ND & ND \\
\hline Skin & $0.010 \pm 0.005$ & ND & ND & $0.014 \pm 0.009$ & ND & ND \\
\hline Skeletal muscle & $0.008 \pm 0.007$ & ND & ND & $0.003 \pm 0.004$ & ND & ND \\
\hline Brain & $<0.001$ & ND & ND & $<0.001$ & ND & ND \\
\hline
\end{tabular}

* The apparent receptor-independent LDL uptake constants $\left(\mathrm{P}^{*}\right)$ are expressed in terms of the micrograms of LDL-cholesterol taken up by a particular organ per hour per gram wet weight of tissue for each $\mathrm{mg} / \mathrm{dl}$ of LDL-cholesterol present in the plasma $\left(C_{1}\right)$. Thus, the product of this constant and the concentration of plasma LDL-cholesterol $(\mathrm{mg} / \mathrm{dl})$ gives the absolute rate of LDL-cholesterol uptake $(\mu \mathrm{g} / \mathrm{h}$ per $\mathrm{g})$ by a particular organ at a specific plasma LDL concentration. These represent the mean values \pm 1 SD obtained from linear regression analysis of data obtained in 13-16 animals (Fig. 3). ¥ The true Michaelis constants $\left(K_{\mathrm{m}}\right)$ for receptor-dependent LDL uptake are given in terms of the concentrations of LDL-cholesterol in the pericellular fluid $\left(C_{2}\right)$ necessary to achieve half-maximal uptake rates. The maximal uptake rates $\left(\mathrm{J}^{\mathrm{m}}\right)$ are expressed as the micrograms of LDL-cholesterol taken up by a particular organ per hour per gram wet weight of tissue. Both constants were derived from nonlinear curves fitted to data obtained in 16 rats and 28 hamsters and variance is given as \pm 1 SD (Fig. 4). As discussed in the text, because of the low values of $\mathrm{R}$ found in each organ, the values of $K_{\mathrm{m}}^{*}$ essentially equal these values of $K_{\mathrm{m}}$. $\S$ Not detected. In these tissues, the receptor-dependent component was so low that the kinetic curves for total LDL-cholesterol uptake could not be distinguished by the curve-fitting program from those obtained for receptor independent uptake: hence, values for $K_{\mathrm{m}}$ and $\mathrm{J}^{\mathrm{m}}$ could not be accurately determined. 
of homologous LDL in the liver, adrenal gland, jejunum, and skeletal muscle of the hamster is shown in Fig. 4. The curves, which have a form dictated by equation 4 , were fitted to each set of experimental data as described in Methods. The configuration of each specific curve is dictated by the magnitude of the receptor-independent component in that organ (P), the $K_{\mathrm{m}}$ and $\mathrm{J}^{\mathrm{m}}$ for the receptor-dependent transport process, and the resistance $(R)$ encountered by the LDL molecule in crossing the capillary diffusion barrier.

Note that the receptor-independent component of these transport curves cannot simply be subtracted from the values for total uptake of LDL to yield the values for the receptordependent component. In any system where the transport sites are separated from the bulk perfusate (plasma) by a significant diffusion barrier (the capillary wall), $C_{2}$ may be significantly higher under circumstances where only the receptor-independent component is being measured (as with methyl-hLDL). When total LDL uptake is quantitated (as with homologous LDL) the presence of the relatively large receptor dependent uptake flux may significantly lower the value of $\mathrm{C}_{2}$. Thus, in the presence of a significant barrier resistance, simple subtraction of the receptor-independent component of LDL uptake would lead to underestimation of the receptor-dependent component in each organ $(29,30)$.

Because of this technical problem, the kinetic parameters for the various transport processes were derived directly from the regression curves fitted to the experimental data points determined in each organ. The goodness of fit to these curves, as judged by the adjusted $r^{2}$ value, was consistently between 0.75 and 0.95 for all organs in each of the two species. Three sets of constants were obtained from such analysis. First, both the $K_{\mathrm{m}}$ and $\mathrm{J}^{\mathrm{m}}$ for the receptor-dependent transport system were determined in a number of organs and these values are also listed in Table I. As is apparent, receptor-mediated LDL uptake was detected in six organs in both the rat and hamster and included the liver, adrenal gland, ovary (in rats), spleen, kidney, and small intestine. $K_{\mathrm{m}}$ for this transport process was essentially the same in all of these organs in both species and varied from 68 to 114 $\mathrm{mg} / \mathrm{dl}$. Furthermore, since $\mathrm{R}$ found in these same organs was low and varied from only $0.0011 \mathrm{~g} \mathrm{~h} / \mathrm{cm}^{3}$ in the spleen to 0.0029

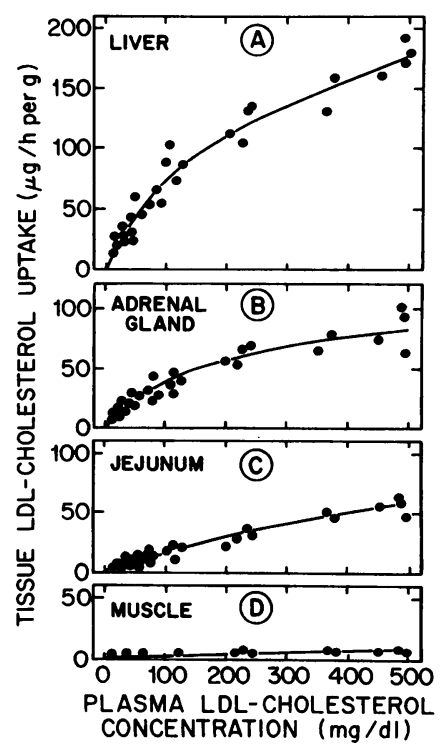

$\mathrm{g} \mathrm{h} / \mathrm{cm}^{3}$ in the intestine, the calculated apparent $K_{\mathrm{m}}$ values $\left(K_{\mathrm{m}}^{*}\right)$ were not significantly different from the true values shown in Table I. Thus, the important conclusion drawn from these measurements was that in all organs with significant receptordependent LDL transport activity, half-maximal uptake rates were achieved at plasma LDL-cholesterol concentrations of $\sim 90$ $\mathrm{mg} / \mathrm{dl}$ so that this transport system would not become saturated until the plasma concentration of LDL was well in excess of 400 $\mathrm{mg} / \mathrm{dl}$. This was true in both the rat and hamster.

In contrast to these $K_{\mathrm{m}}$ values, there were significant differences in maximal transport rates in the different organs. Clearly, the highest values were found in the liver and endocrine glands in both the rat and hamster while much lower maximal transport rates were detected in the other organs. Note, however, that when organ weight was taken into consideration, only two of these tissues, the liver and, to a lesser extent, the small intestine, were quantitatively important in the receptor-dependent removal of LDL from the plasma.

Secondly, analysis of these same curves also yielded values for the true receptor-independent uptake constants $(P)$ as determined with the homologous LDL preparation and provided the opportunity, therefore, to compare these values with those determined with methyl-hLDL. For example, in the spleen and jejunum of the hamster, two organs with relatively high receptorindependent uptake rates, the values of $\mathbf{P}$ measured with hamLDL equaled 0.37 and $0.09 \mu \mathrm{g} / \mathrm{h}$ per $\mathrm{g}$ per $\mathrm{mg} / \mathrm{dl}$, respectively. These values were essentially identical to the values of $\mathrm{P}^{*}$ determined directly with methyl-hLDL, i.e., 0.34 and 0.08 $\mu \mathrm{g} / \mathrm{h}$ per $\mathrm{g}$ per $\mathrm{mg} / \mathrm{dl}$, respectively, (Table I) and added further support to the validity of using this methylated heterologous LDL preparation for measuring receptor-independent lipoprotein transport in various experimental animals.

Thirdly, analysis of these transport curves also provided data from which the concentration of LDL at the parenchymal cell surface could be calculated. The absolute magnitude of the resistance terms determined in these seven organs and substituted into equation 1 gave the value of $C_{2}$ at each value of $C_{1}$ and $J_{t}$. These calculated values of $C_{2}$ proved to be essentially equal to $C_{1}$ at all values of $J_{t}$ in the major organs like liver, spleen, kidney, intestine, and the endocrine glands. In addition, the near identity of the values of $\mathbf{P}$ and $\mathrm{P}^{*}$ also strongly supported the conclusion that the concentration of LDL perfusing the parenchymal cell surface $\left(C_{2}\right)$ of these organs was very nearly the same as the concentration of the lipoprotein in the bulk phase of the capillary plasma $\left(C_{1}\right)$.

\section{Discussion}

These studies provide the first quantitative description of the kinetics of the receptor-dependent and receptor-independent processes that remove LDL from the plasma under in vivo conditions. These measurements were carried out in two species, the rat and hamster, commonly used in studies of cholesterol and lipoprotein metabolism and which differ markedly in their metabolic characteristics. The rat has an exceptionally high capacity to alter absolute rates of cholesterol synthesis and degradation, and so responds to alterations in cholesterol balance across a given organ or the whole animal by changing one of these processes. Hence, there is seldom regulation of LDL transport activity in this species so that plasma LDL-cholesterol levels remain remarkably constant under a variety of experimental 
conditions $(10,31,32)$. The male hamster, on the other hand, behaves very much like man, in that it has a much lower capacity to alter absolute rates of cholesterol synthesis and degradation and so is forced to regulate LDL transport activity in response to the intake of dietary cholesterol or saturated fatty acids (11) or to alterations in the bile acid pool induced by cholestyramine $(9,10)$ or bile acid feeding $(13,26)$. Despite these marked quantitative differences in cholesterol metabolism between the rat and hamster, however, the present studies demonstrated that the various aspects of LDL transport were quantitatively very similar in these two species. This observation provides further support for the concept that the cellular regulation of cholesterol synthesis and degradation is independent of the regulation of LDL transport activity $(3,10)$.

Receptor-dependent LDL transport accounts for the uptake of $60-80 \%$ of the lipoprotein that is degraded each day in the normal experimental animal and in man (5-10). In the rat and hamster, respectively, this receptor-dependent process clears $\sim 500$ and $400 \mu$ l of plasma of its LDL content per hour per $100 \mathrm{~g}$ body weight $(4,9,10) . \sim 70 \%$ of this transport activity is found in the liver in the rat while $>90 \%$ of receptor-dependent LDL transport detected in the hamster is accounted for by uptake in this organ. Despite this overwhelming importance of the liver, receptor-dependent LDL transport also has been identified in vivo in other organs, including the endocrine glands, spleen, kidney, small bowel, lung, and colon in the rat, hamster and rabbit (Spady, D. K., J. B. Meddings, and J. M. Dietschy, unpublished observations) $(4,9)$. In the present study it was possible to define the transport kinetics for the receptor-dependent process in six of these tissues, but in lung and colon this component of LDL uptake was so low that it could not be distinguished from the receptor-independent process.

When expressed per unit weight of tissue, the highest $\mathrm{J}^{\mathrm{m}}$ values observed in both the rat and hamster were found in the liver (90-126 $\mu \mathrm{g} / \mathrm{h}$ per $\mathrm{g}$ ) and adrenal gland (55-103), followed by the ovary (50), spleen (15-35), kidney (6-37), and small intestine (7-17) (Table I). In contrast, the $K_{\mathrm{m}}$ values for this transport system were essentially the same in these organs and, again, were nearly identical in both species, equaling $\sim 90 \mathrm{mg} / \mathrm{dl}$ (Table I). Because of these high $K_{\mathrm{m}}$ values, the plasma LDL-cholesterol level would have to exceed $400 \mathrm{mg} / \mathrm{dl}$ before essentially saturating the receptor-dependent system in these tissues. Stated differently, in the range of plasma LDL-cholesterol levels commonly encountered in these experimental animals, the rate of receptordependent LDL transport would continue to increase, in a curvilinear fashion, as the plasma LDL concentration increased (see Figs. 2 and 4) so that this transport system would seldom, if ever, become saturated under physiological or even pathological conditions.

In contrast to this receptor-dependent system, the receptorindependent transport of LDL by the various tissues of both the rat and hamster was a linear function of the plasma LDL concentration (Figs. 2 and 3) so that the clearance of LDL by this process was constant (Fig. 2 B) (4). Furthermore, receptorindependent LDL uptake could be detected in every tissue and the proportionality constant $\left(\mathrm{P}^{*}\right)$ that described uptake was very similar in any given organ in these two species (Table I). The values of $P^{*}$ were highest in the spleen $(0.34-0.56 \mathrm{mg} / \mathrm{h}$ per $\mathrm{g}$ per $\mathrm{mg} / \mathrm{dl})$, liver (0.08-0.09), and small intestine (0.08-0.09) and lower in most other organs. In particular, LDL uptake by adipose tissue (0.011-0.012), skin (0.010-0.014), skeletal muscle $(0.003-0.008)$, and brain $(<0.001)$ was at the lower limit of the method to detect LDL uptake. When whole organ weight was taken into consideration, receptor-independent LDL transport activity was more widely distributed in the body than receptordependent transport so that, in contrast to receptor-dependent uptake, a number of extrahepatic organs was quantitatively important in this process (4).

In the analysis of these transport data, it was also extremely important to have some quantitative measurement of the resistance encountered by the LDL molecule in moving from the bulk phase of the plasma to the transport sites on the parenchymal cells since, if this $\mathrm{R}$ term were high, the $K_{\mathrm{m}}$ values for the receptor-dependent uptake process would be grossly overestimated and the $P$ values would be underestimated. Three lines of evidence, however, suggest that the $R$ term was negligible, at least in the liver, spleen, endocrine glands, kidney, and small intestine. First, $K_{\mathrm{m}}^{*}$ values in organs with intact capillaries like kidney and intestine were essentially identical to those values found in the liver and spleen where the resistance term should equal essentially 0 . Second, the values of $P$ and $P^{*}$, which in several organs were independently measured, were essentially the same. Third, direct estimates of the $R$ term from the analysis of homologous LDL transport in each organ (Fig. 4) were all equal to or less than $0.003 \mathrm{~g} \mathrm{~h} / \mathrm{cm}^{3}$. These values of $R$ were so small, relative to the values of $J_{t}$ in each organ, that when substituted into equation 1 the calculated values of $C_{2}$ were not significantly less than $C_{1}$. Thus, at least in these seven tissues, the movement of LDL across the capillary, either through junctional complexes or by means of vesicular transport, must have been sufficiently rapid, relative to the rate of transport into the parenchymal cells, so as to maintain $C_{2}$ nearly equal to $C_{1}$. This may not be true, however, in other organs such as the adipocyte, skin, and particularly, skeletal muscle and brain that have no demonstrable receptor-dependent transport and very low rates of receptor-independent uptake (Table I). In such tissues it is conceivable that it is the resistance to LDL movement across the diffusion barriers of the capillary that limits net transport rather than an absence of specific transport mechanisms on the parenchymal cells. Regardless of the reason, however, such organs take up little or no LDL-cholesterol under in vivo conditions.

Using these kinetic data derived for each organ, it was possible to construct theoretical curves that described the behavior of the various parameters of LDL metabolism in the whole animal under essentially all conditions that might be encountered when the experimental animal is subjected to a variety of environmental, physiological, or pharmacological manipulations. Fig. 5 illustrates such curves in the case of the male hamster. To construct these curves, the number of receptor-dependent transport sites, i.e., the value of $J^{m}$ in each organ, was kept constant while the plasma LDL cholesterol concentration was varied from 0 to $500 \mathrm{mg} / \mathrm{dl}$. The amount of LDL-cholesterol taken up by each organ at each plasma LDL concentration was calculated using the values of $\mathrm{P}^{*}, \mathrm{~J}^{\mathrm{m}}$, and $K_{\mathrm{m}}$ appropriate for that tissue, and such values derived for all organs were then summed to give the data shown in Fig. 5 for the whole animal. The solid line in Fig. $5 \mathrm{~A}$ shows the total rate of LDL-cholesterol removal from the plasma (which also equals the metabolic production rate of LDL-cholesterol) at any concentration of plasma LDLcholesterol, while the dashed line shows that portion which is receptor-independent. Fig. $5 B$ presents these same data expressed as either whole animal clearance rates or as fractional catabolic rates (FCR), while Fig. $5 C$ shows the percentage of total LDL- 


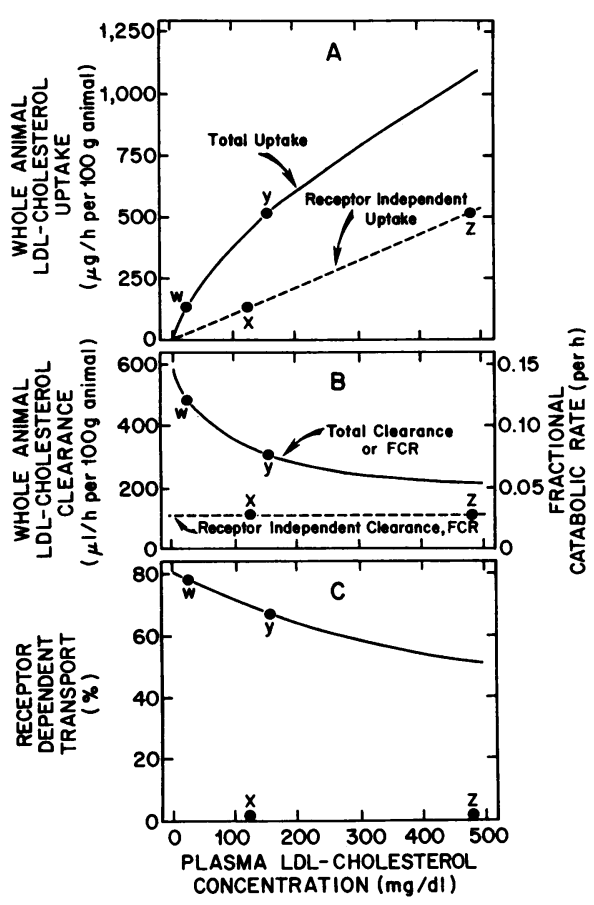

Figure 5. Kinetic curves for the transport of LDL out of the plasma space in the whole hamster weighing $100 \mathrm{~g}$. $A$ shows the absolute rates of LDL-cholesterol removal (degradation) from the plasma space as a function of the plasma LDL-cholesterol concentration under circumstances where LDL receptor activity in all organs was constant. Both total and receptor-independent LDL uptake are shown. In $B$ these same data are presented as whole animal clearance rates and as fractional catabolic rates. In $C$, the percentage of total $\mathrm{LDL}$ clearance that is receptor-dependent is plotted as a function of the plasma LDL-cholesterol concentration. The specific points labeled $\mathrm{w}, \mathrm{x}, \mathrm{y}$, and $\mathrm{z}$ refer to situations in which there have been changes in LDL receptor activity and/or LDL production rates in the whole animal, and these are discussed in detail in the text.

cholesterol uptake from the plasma that is receptor-dependent in this species. Two points concerning these curves warrant emphasis. First, the receptor-independent component of LDL-cholesterol degradation is a linear function of the plasma LDLcholesterol concentration (Fig. $5 A$ ) and, therefore, this component is constant when expressed as either a clearance value (108 $\mu \mathrm{l} / \mathrm{h}$ per $100 \mathrm{~g}$ animal) or as a FCR $(0.026 \mathrm{per} \mathrm{h})$. Second, under these circumstances where the number of $L D L$ receptors in each organ was kept constant, it is apparent that the plasma LDL clearance rate and FCR (Fig. $5 \mathrm{~B}$ ) and the percentage of LDL degraded by the receptor dependent process (Fig. $5 C$ ) decreases markedly as the plasma LDL-cholesterol level is increased.

The points labeled $w$ in Fig. 5 show the position of the normal male hamster fed a low-cholesterol diet. Such animals have a mean plasma LDL-cholesterol concentration of $\sim 25 \mathrm{mg} / \mathrm{dl}$, and synthesize and degrade $\sim 127 \mu \mathrm{g}$ of LDL-cholesterol per $\mathrm{h}$ per $100 \mathrm{~g}$ animal (Fig. $5 \mathrm{~A}$ ). This corresponds to a LDL-cholesterol clearance rate of $509 \mu \mathrm{l} / \mathrm{h}$ per $100 \mathrm{~g}$ and an FCR of 0.12 per $\mathrm{h}$ (Fig. $5 \mathrm{~B}$ ), and $79 \%$ of this clearance is receptor-dependent (Fig. $5 C$ ). The points labeled $x$ represent the situation where all $\mathrm{LDL}$ receptor activity was eliminated but the LDL production (and uptake) rate was kept constant at $127 \mu \mathrm{g} / \mathrm{h}$ per $100 \mathrm{~g}$. In this case, the plasma LDL-cholesterol concentration would rise about fivefold, to $119 \mathrm{mg} / \mathrm{dl}$ (Fig. $5 A$ ), the clearance rate and FCR would decrease to $108 \mu \mathrm{l} / \mathrm{h}$ per $100 \mathrm{~g}$ and $0.026 \mathrm{per} \mathrm{h}$, respectively (Fig. 5 B), and all LDL degradation would take place by receptorindependent mechanisms (Fig. $5 C$ ). The points labeled y represent the situation where the production rate of LDL was increased fourfold, to $508 \mu \mathrm{g} / \mathrm{h}$ per $100 \mathrm{~g}$, under circumstances where total LDL receptor activity was maintained constant at the control level. In this case, the plasma LDL-cholesterol concentration would increase to $158 \mathrm{mg} / \mathrm{dl}$ (Fig. $5 \mathrm{~A}$ ), the LDLcholesterol clearance rate and FCR would decrease to $322 \mu \mathrm{l} / \mathrm{h}$ per $100 \mathrm{~g}$ and 0.078 per $\mathrm{h}$, respectively, and only $68 \%$ of the LDL would be removed from the plasma by the receptor-dependent process. The points labeled $\mathrm{z}$ represent the situation where both of these pathological conditions were present together, i.e., the situation where LDL production was increased fourfold and all receptor-dependent transport activity was absent. In this case the plasma LDL-cholesterol concentration would increase markedly to $\sim 480 \mathrm{mg} / \mathrm{dl}$.

From these quantitative considerations, there are four major points concerning the regulation of plasma LDL-cholesterol levels that should be emphasized. First, the whole animal clearance rate or FCR will be altered markedly under any circumstance where there has been a change in the number of LDL receptors $\left(\mathrm{J}^{\mathrm{m}}\right)$, a change in the LDL production rate, a change in the affinity of the LDL molecule for its transport system $\left(K_{\mathrm{m}}\right)$, or where other competing lipoproteins might be present. Thus, it is impossible to draw any conclusions about receptor-dependent LDL transport activity in the whole animal (or in man) based solely upon measurements of fractional catabolic rates. Second, marked changes in either the activity of receptor-dependent LDL transport or the LDL metabolic production rate alone result in only modest alterations in the plasma LDL-cholesterol level (Fig. 5). For example, in man or the experimental animal the plasma LDL-cholesterol level would never rise more than 3-4 times the normal value if all receptor activity were lost but the LDL production rate were kept constant. However, the plasma LDL cholesterol level would increase markedly when loss of LDL receptor activity was coupled with overproduction of this lipoprotein. These two factors presumably account for the very high plasma cholesterol concentrations seen in patients with homozygous familial hypercholesterolemia and may also be important when overproduction and loss of hepatic LDL receptor activity is induced by dietary manipulations (11). Third, in the normal animal from 65 to $80 \%$ of LDL clearance from the plasma takes place in the liver and intestine $(4,9)$. Hence, LDL probably should be viewed simply as the remnant of the very low density lipoprotein particle which, under normal circumstances, should be rapidly removed from the plasma and excreted into the gastrointestinal tract. Fourth, since $70-90 \%$ of receptor-dependent LDL transport activity is found in the liver and intestine $(4,9)$, loss of this activity, through either genetic or dietary factors, would necessarily shift the burden of LDL clearance to the more peripheral organs (4).

Thus, the kinetic data presented in this study provide the quantitative basis for predicting the behavior of the plasma LDLcholesterol concentration under circumstances where a specific alteration has been induced in the receptor dependent or receptor independent transport of LDL in any organ, where the LDL production rate has been changed, or where competing lipoproteins or a change in the structure of the LDL molecule has led to an alteration in the affinity of LDL for its receptor. Furthermore, methods are now available for quantitating each of these 
pathways in the live animal so that such predictions can be verified under in vivo conditions $(4,9-11)$. Taken together, these various techniques should allow a detailed understanding of how virtually any environmental, dietary, or pharmacological manipulation actually leads to a change in circulating LDL-cholesterol levels.

\section{Acknowledgments}

This work was supported by U. S. Public Health Service Research grants HL 09610 and AM 19329 and by grants from the Moss Heart Fund and the American Heart Association, Texas Affiliate grant G155. Dr. Spady is a recipient of Clinical Investigator Award AM )1221 from the U. S. Public Health Service. Dr. Meddings is supported by an Alberta Heritage Foundation grant.

\section{References}

1. Grundy, S. M. 1982. Hypertriglyceridemia: Mechanisms, clinical significance, and treatment. In Medical Clinics of North America. R. J. Havel, editor. W. B. Saunders Company, Philadelphia, PA. 66:519-535.

2. Goldstein, J. L., and M. S. Brown. 1984. Progress in understanding the LDL receptor and HMG-CoA reductase, two membrane proteins that regulate the plasma cholesterol. J. Lipid Res. 25:1450-1461.

3. Dietschy, J. M. 1984. Regulation of cholesterol metabolism in man and in other species. Klin. Wochenschr. 62:338-345.

4. Spady, D. K., S. D. Turley, and J. M. Dietschy. 1985. Receptorindependent low density lipoprotein transport in the rat in vivo. Quantitation, characterization, and metabolic consequences. J. Clin. Invest. In press.

5. Koelz, H. R., B. C. Sherrill, S. D. Turley, and J. M. Dietschy. 1982. Correlation of low and high density lipoprotein binding in vivo with rates of lipoprotein degradation in the rat. A comparison of lipoproteins of rat and human origin. J. Biol. Chem. 257:8061-8072.

6. Pittman, R. C., T. E. Carew, A. D. Attie, J. L. Witztum, Y. Watanabe, and D. Steinberg. 1982. Receptor-dependent and receptor-independent degradation of low density lipoprotein in normal rabbits and in receptor-deficient mutant rabbits. J. Biol. Chem. 257:7994-8000.

7. Bilheimer, D. W., Y. Watanabe, and T. Kita. 1982. Impaired receptor-mediated catabolism of low density lipoprotein in the WHHL rabbit, an animal model of familial hypercholesterolemia. Proc. Natl. Acad. Sci. USA. 79:3305-3309.

8. Kesaniemi, Y. A., J. L. Witztum, and U. P. Steinbrecher. 1983. Receptor-mediated catabolism of low density lipoprotein in man. Quantitation using glucosylated low density lipoprotein. J. Clin. Invest. 71: 950-959.

9. Spady, D. K., D. W. Bilheimer, and J. M. Dietschy. 1983. Rates of receptor-dependent and -independent low density lipoprotein uptake in the hamster. Proc. Natl. Acad. Sci. USA. 80:3499-3503.

10. Spady, D. K., S. D. Turley, and J. M. Dietschy. 1985. Rates of low density lipoprotein uptake and cholesterol synthesis are regulated independently in the liver. J. Lipid Res. 26:465-472.

11. Spady, D. K., and J. M. Dietschy. 1985. Dietary saturated triacylglycerols suppress hepatic low density lipoprotein receptor activity in the hamster. Proc. Natl. Acad. Sci. USA. 82:4526-4530.

12. Dietschy, J. M., S. D. Turley, and D. K. Spady. 1983. The role of the liver in lipid and lipoprotein metabolism. In Falk Symposium 35. Liver in Metabolic Diseases. L. Bianchi, W. Gerok, L. Landmann, K. Sickinger, and G. A. Stalder, editors. MTP Press Limited, Boston/The Hague/Dordrecht/Lancaster. 25-39.

13. Spady, D. K., E. F. Stange, L. E. Bilhartz, and J. M. Dietschy. 1986. Bile acids regulate hepatic low density lipoprotein receptor activity in the hamster by altering cholesterol flux across the liver. Proc. Natl. Acad. Sci. USA. In press.

14. Stange, E. F., and J. M. Dietschy. 1984. Age-related decreases in tissue sterol acquisition are mediated by changes in cholesterol synthesis and not low density lipoprotein uptake in the rat. J. Lipid Res. 25:703713.

15. Mahley, R. W., K. H. Weisgraber, G. W. Melchior, T. L. Innerarity, and K. S. Holcombe. 1980. Inhibition of receptor-mediated clearance of lysine and arginine-modified lipoproteins from the plasma of rats and monkeys. Proc. Natl. Acad. Sci. USA. 77:225-229.

16. Munford, R. S., J. M. Andersen, and J. M. Dietschy. 1981. Sites of tissue binding and uptake in vivo of bacterial lipopolysaccharide-high density lipoprotein complexes. Studies in the rat and squirrel monkey. J. Clin. Invest. 68:1503-1513.

17. Turley, S. D., J. M. Andersen, and J. M. Dietschy. 1981. Rates of sterol synthesis and uptake in the major organs of the rat in vivo. $J$. Lipid Res. 22:551-569.

18. Dietschy, J. M., and D. K. Spady. 1984. Measurement of rates of cholesterol synthesis using tritiated water. J. Lipid Res. 25:1469-1476.

19. Westergaard, H., and J. M. Dietschy. 1974. Delineation of the dimensions and permeability characteristics of the two major diffusion barriers to passive mucosal uptake in the rabbit intestine. J. Clin. Invest. 54:718-732.

20. Dietschy, J. M. 1978. General principles governing movement of lipids across biological membranes. In Disturbances in Lipid and Lipoprotein Metabolism. J. M. Dietschy, A. M. Gotto, and J. A. Ontko, editors. Waverly Press, Inc., Baltimore, MD. 1-28.

21. Thomson, A. B. R., and J. M. Dietschy. 1977. Derivation of the equations that describe the effects of unstirred water layers on the kinetic parameters of active transport processes in the intestine. J. Theor. Biol. 64:277-294.

22. Thomson, A. B. R., and J. M. Dietschy. 1984. The role of the unstirred water layer in intestinal permeation. In Handbook of Experimental Pharmacology, Vol. 70/II. T. Z. Csaky, editor. Springer-Verlag, Germany. 165-269.

23. Wentworth, W. E. 1965. Rigorous least squares adjustment. Application to some non-linear equations. J. Chem. Educ. 42:96-103.

24. Túrley, S. D., D. K. Spady, and J. M. Dietschy. 1983. Alteration of the degree of biliary cholesterol saturation in the hamster and rat by manipulation of the pools of preformed and newly synthesized cholesterol. Gastroenterology. 84:253-264.

25. Spady, D. K., and J. M. Dietschy. 1983. Sterol synthesis in vivo in 18 tissues of the squirrel monkey, guinea pig, rabbit, hamster, and rat. J. Lipid Res. 24:303-315.

26. Spady, D. K., S. D. Turley, and J. M. Dietschy. 1983. Comparison of the role of hepatic cholesterol synthesis and lipoprotein cholesterol uptake in determining the rate of biliary cholesterol secretion in the hamster. In Falk Symposium 33. Bile Acids and Cholesterol in Health and Disease. G. Paumgartner, A. Stiehl, and W. Gerok, editors. MTP Press Limited, Hingham, MA. 157-173.

27. Innerarity, T. L., R. E. Pitas, and R. W. Mahley. 1980. Disparities in the interaction of rat and human lipoproteins with cultured rat fibroblasts and smooth muscle cells. Requirements for homology and receptor binding activity. J. Biol. Chem. 255:11163-11172.

28. Mahley, R. W., K. H. Weisgraber, G. W. Melchior, T. L. Innerarity, and K. S. Holcombe. 1980. Inhibition of receptor-mediated clearance of lysine and arginine-modified lipoproteins from the plasma of rats and monkeys. Proc. Natl. Acad. Sci. USA. 77:225-229.

29. Winne, D. 1977. Correction of the apparent Michaelis constant, biased by an unstirred layer, if a passive transport component is present. Biochim. Biophys. Acta. 464:118-126.

30. Westergaard, H., K. H. Holtermuller, and J. M. Dietschy. 1986. Measurement of the resistance of the barriers to solute transport in vivo in the jejunum of the rat. Am. J. Physiol. In press.

31. Weis, H. J., and J. M. Dietschy. 1974. Adaptive responses in hepatic and intestinal cholesterogenesis following ileal resection in the rat. Eur. J. Clin. Invest. 4:33-41.

32. Dietschy, J. M., and J. D. Wilson. 1970. Regulation of cholesterol metabolism. N. Engl. J. Med. 282:1128-1138, 1179-1183, 1241-1249. 